- 数据论文・

\title{
生物多样性数据论文发表趋势分析
}

\author{
李俊洁 黄晓䂞 ${ }^{*}$ \\ (福建农林大学植物保护学院, 闽台作物有害生物生态防控国家重点实验室, 福州 350002)
}

\begin{abstract}
摘要: 近年来有关科学数据共享的呼声越来越高, 基于同行评审的生物多样性数据论文也受到越来越多的关注, 并出现了一些专门发表数据论文的数据期刊。本文总结了近年来生物多样性数据发表方面的进展, 选择两本代表 性数据期刊(Biodiversity Data Journal和Scientific Data), 分析了它们自创刊以来的发文数量、涉及生物类群、文章 测览量和被引次数等指标。结果显示两本数据期刊的发文量都呈稳步增长趋势, 其生物多样性数据论文覆盖了包 括动物界、植物界、真菌界在内的众多生物类群, 文章汶览量和被引次数方面也有可喜的表现, 说明数据论文正 在被越来越多的研究者所接受。对文章作者国别的分析则显示了不同地区的研究者在发表生物多样性数据论文或 数据共享方面的不均衡。建议相关领域的中国研究者和期刊关注生物多样性数据论文和数据共享政策, 更多地践 行数据共享。
\end{abstract}

关键词: 数据共享; 数据期刊; 开放科学; 生态学; 文献计量学

\section{Analysis of publication trends of biodiversity data papers}

\author{
Junjie Li, Xiaolei Huang* \\ State Key Laboratory of Ecological Pest Control for Fujian and Taiwan Crops, College of Plant Protection, Fujian Agri- \\ culture and Forestry University, Fuzhou 350002
}

\begin{abstract}
In recent years, there have been more and more appeals for sharing of biodiversity data. 'Biodiversity data paper' has been proposed as a reward mechanism for sharing data by individual scientists. Some data journals dedicated to publishing data papers have been founded. In this paper, we analyze the number of articles, coverage of biological groups, article views, and citations of two representative data journals (Biodiversity Data Journal and Scientific Data). Results show that the number of articles in both data journals has been steadily increasing. Biodiversity data papers cover a wide range of biological groups in Animalia, Plantae and Fungi. The article views and citations also show encouraging performance. These results indicate that data papers are being accepted by more and more researchers. Analysis of author regions of biodiversity data papers indicates a disequilibrium in the data sharing culture among different geographical regions. We suggest Chinese researchers and journals in related fields pay more attention to biodiversity data papers and trends of data sharing policies, as well as improving data sharing practices.
\end{abstract}

Key words: data sharing; data journal; open science; ecology; bibliometrics

大科学时代的来临以及人类所面临的环境问 题对生物多样性和生态学提出了新的要求, 科学家 不但要通过大尺度研究来理解众多全球性问题(如 多样性丧失、气候变化、粮食安全), 而且要基于科 学证据提出相应的对策(Michener \& Jones, 2012; Hampton et al, 2013)。然而, 如何有效地共享及整合
生物多样性数据成为解决这些重要生物多样性和 生态学问题所面临的重要挑战(黄晓否和乔格侠, 2014)。生物多样性数据共享不但是提升生物多样性 研究的深度和广度、开展整合性研究的需要 (Reichman et al, 2011; Hampton et al, 2013), 而且是 检验生态学研究可重复性(Cassey \& Blackburn,

收稿日期: 2016-11-16; 接受日期: 2016-12-06

基金项目: 国家自然科学基金(31272348)和福建省杰出青年科学基金(2015J06005)

* 通讯作者 Author for correspondence. E-mail: huangxl@fafu.edu.cn 
2006; Ryan, 2011; Shapiro \& Báldi, 2012)和科学制 定生物多样性和环境政策的重要基础(Pullin \& Salafsky, 2010; Haddaway \& Pullin, 2013)。

作为最主要的数据生产者、分享者和使用者, 科学家群体的态度和行为在很大程度上决定了数 据共享的效果。Vines等(2014)调查了1991-2011年间 发表的516篇生态学论文, 结果发现这些论文数据 的可获得性受到文章已发表时长的严重影响, 且以 每年 $17 \%$ 的速度递减。这项研究体现了科学数据共 享的重要性, 也说明科学数据的长期保存需要公共 数据库和数据政策的支持。Huang等(2012)开展的一 项国际调研发现, 生物多样性领域的数据分享文化 并不发达, 科学家面临一些技术和认知上的障碍 (比如同行竞争、不熟悉数据保存机构、缺少时间和 经费来管理数据等), 而且科学家希望能从数据共 享中获得相应的回报。最近由Digital Science、

Springer Nature和Figshare联合发布的一份有关科学 数据共享的报告也反映了研究者面临的技术和认 知障碍, 而且近 $70 \%$ 的研究者认为数据引用和论文 引用应该具有同等价值(Fane et al, 2016)。

推进生物多样性数据共享仅仅靠增强生物多 样性数据所有利益方(科研工作者、研究和资助机 构、期刊等)对于数据共享价值的认识是远远不够 的, 同时也需要所有利益方积极采取有效的共享策 略。近年来新出现了几种数据共享策略, 包括Dryad (http://datadryad.org/)和Figshare(http://figshare.com/) 等数据保存机构集中保存论文数据、生物多样性数 据论文和数据期刊(Chavan \& Penev, 2011; Costello et al, 2013)、期刊和数据保存机构间的联合数据保 存政策(Huang \& Qiao, 2011; De Wever et al, 2012) 等。这些数据共享策略大多从增加数据共享者的收 益(如数据集的所有权和可引用性)出发, 取得了一 定的效果。这其中, 生物多样性数据论文采用科研 工作者熟知的学术出版形式, 与科研工作的关系密 切，是本文关注的对象。

生物多样性数据论文由全球生物多样性信息 网络(Global Biodiversity Information Facility, GBIF) 和学术出版商Pensoft在2011年联合提出, 主要目的 是“用于网络共享的数据集的元数据文件可以采用 学术论文的形式发表”, 从而为数据共享、数据质量 控制和改善科研评价提供一个有效的方法。2013年 9月, Pensoft创办了数据期刊Biodiversity Data Jour- nal (BDJ, http://bdj.pensoft.net/), 专门用于发表生物 多样性数据论文, 论文的数据集则可以无缝分享到 GBIF。近两三年在生物医学、地球科学、基因组学 等领域也出现了专门发表数据论文的数据期刊。最 为突出的是, 自然出版集团 (Nature Publishing Group)也于 2014年3月开始正式出版综合性数据 期刊 Scientific Data (SD, http://www.nature.com/ sdata/)。

作为较新的数据共享方式, 生物多样性数据论 文被研究者接受的程度如何? 数据期刊发表论文 的数量有什么趋势? 数据论文被使用或引用的情 况如何? 回答这些问题有助于增进研究者对数据 论文的认识和理解。为此, 本文选择了两本代表性 数据期刊 (Biodiversity Data Journal 和 Scientific Data), 分析了它们创刊以来的发文数量、涉及生物 类群、文章浏览量和被引用次数等指标, 以期基于 实证数据揭示数据论文的发表趋势。

\section{1 资料来源与研究方法}

\section{1 研究对象}

本研究主要关注发表生物多样性相关数据论 文的两本代表性数据期刊Biodiversity Data Journal (BDJ)和Scientific Data (SD)。BDJ自2013年9月16日 开始出版, 旨在基于同行评审的学术出版模式, 快 速发表生物多样性数据。BDJ发表的文章类型主要 包括Data Paper (数据论文)、Taxonomic Paper (分类 论文)、General Article (综合论文)、Software Description (软件描述)、Species Inventory (物种目录)、 Interactive Key (交互式检索表)等。BDJ要求所有基 于原始数据的论文以符合规范的形式共享数据, 因 此虽然有文章类型的人为划分，它们(除 Software Description外)的区别更多的只是所共享数据的类 型和多少，实际上都属于数据论文的范畴。BDJ发 表的文章涉及物种分类和标本信息、生物区系数据 库、植被组成、形态特征、鸣声记录、DNA条形码 等多种生物多样性数据类型。SD自2014年3月11日 开始出版，作为自然出版集团力推的综合性数据期 刊, 主要发表具有重要科学价值、数据量大的原始 数据集及其分析(Data Descriptor), 面向众多科学 领域。

本研究期望基于对BDJ的分析揭示生物多样性 数据论文的发表和使用趋势，对 SD的分析则可以 
从更广泛的角度揭示数据论文的发表情况, 因此未 单独提取生物多样性相关领域文章。

\section{2 数据收集}

$\mathrm{BDJ}$ 和SD均为在线出版期刊, 本研究的数据主 要基于两本期刊网站提供的文献计量指标, 收集了 两本期刊自创刊截止到2016年6月17日的文献信 息。BDJ文章信息包括每篇文章的出版时间、文章 类型、涉及生物类群、作者国别、文章内容、汶览 量等6个方面; SD文章信息包括每篇文章的出版时 间、文章类型、浏览量、引用量等 4 个指标。使用 微软Excel软件对以上信息进行分类整理及校对, 最终获得的BDJ原始数据集包含313条文献、1,878 个数据项, SD数据集包含174条文献、696个数据项。 本文的原始数据集共享在 Figshare, 链接为: https://figshare.com/articles/Data_papers/4311917/。同 时, 也以本文附录材料的形式共享在 《生物多样性》 网站(附录1)。

\section{3 数据分析}

基于所获得的原始数据集, 主要开展了 4 个方 面的分析:

(1) BDJ和SD两本数据期刊在时间序列上的发 文量趋势。为更好地揭示发文趋势, 最初比较分析 了按“每月”和“每2月”绘制的折线图, 发现以每2月 为划分标准能更好地反映发文量趋势。由于BDJ有 些文章类型的发文数量极少, 最终反映发文趋势的 折线图中主要呈现Taxonomic Paper、Data Paper、 General Article、Software Description 4种文章类型以 及它们的总和。对于 SD来说, Data Descriptor是其主 要发文类型(占93.7\%), 因此发文趋势对Data Descriptor文章进行了分析。另外值得指出的是, 按照 本文对两本期刊统计的时间范围, 趋势图中最后一 个时间段仅约为 1 个月。

(2) BDJ发表论文所涉及生物类群的多样性。 BDJ发文数量前三位的Taxonomic Paper、Data Paper、General Article均报道生物多样性原始数据, 因 此对这些文章进行了生物类群多样性分析。依次提 取每篇文章提及的生物类群, 并确定其所属的纲。 由于昆虫纲所占比例较大, 进而将昆虫类群具体到 目开展分析。

(3) BDJ发表论文的作者国别。作者国别的统计 有助于了解不同地区研究者对于数据论文及数据 共享的态度, 以论文作者单位地址为数据源统计了
BDJ文章作者国别信息, 并按发文数量进行排序。

（4）BDJ和SD发表论文的被使用情况。考虑到 BDJ和SD网站均提供了文章汶览量信息, SD网站还 提供了文章被引用数据, 本文主要分析了两本期刊 文章的汶览量和 SD文章的被引次数, 以此来了解 数据论文被使用的情况。采用网站提供的唯一身份 浏览量(unique view)对不同类型文章的汶览量进行 了分析，该指标比总访问量(total view)更能客观揭 示论文被使用的情况。结果中主要呈现BDJ发文量 较多的4种文章类型(Taxonomic Paper, Data Paper, General Article, Software Description)。SD网站提供 了分别来自CrossRef和Scopus的文章引用数据, 由 于这两个数据库覆盖的期刊范围有所差别, 引文数 据也略有差别, 但总体引用量常基本一致。我们比 较分析了每篇Data Descriptor来自这两个数据库的 引用情况。

\section{2 结果}

\subsection{BDJ和SD在时间序列上的发文趋势}

在本文统计的时间范围内, BDJ 共发表 Taxonomic Paper 218篇、Data Paper 38篇、General Article 36篇、Software Description 11篇、Species Inventory 3篇、Corrigendum 3篇、Editorial 3篇、 Interactive Key 1篇。由图1a可以看出, 自创刊以来, $\mathrm{BDJ}$ 不同类型文章数量虽有波动, 但总体发文量(红 线)呈上升趋势, 2014、2015、2016年(截至6月中旬) 每2月平均发文数量分别为13.3篇、18.6篇、25.5篇。 统计时间内, SD共发表Data Descriptor 163篇, 发文 数量总体呈稳步增加趋势(图1b), 2014、2015、2016 年(截至6月中旬)每 2 月平均发文数量分别为 10 篇、 12.3篇、15篇。

\subsection{BDJ论文涵盖的生物类群}

BDJ所发表的报道生物多样性原始数据的文章 (Taxonomic Paper、Data Paper、General Article)共涉 及动物界的26纲、植物界的3纲、真菌界的2纲(图 2a)。其中报道昆虫纲的文章远多于其他类群, 达 185篇; 其次为蛛形纲14篇, 双子叶植物纲10篇。基 于目级单元对昆虫纲185篇文章进一步分析发现(图 $2 b)$, 报道膜翅目和双翅目的文章占一半以上, 有关 鞘翅目和半翅目的文章也较多。按文章数量多少排 序依次为: 膜翅目63篇, 双翅目 47 篇, 鞘翅目 24 篇, 半翅目 18 篇, 鳞翅目 10 篇, 脉翅目 4 篇, 直翅目和螳 


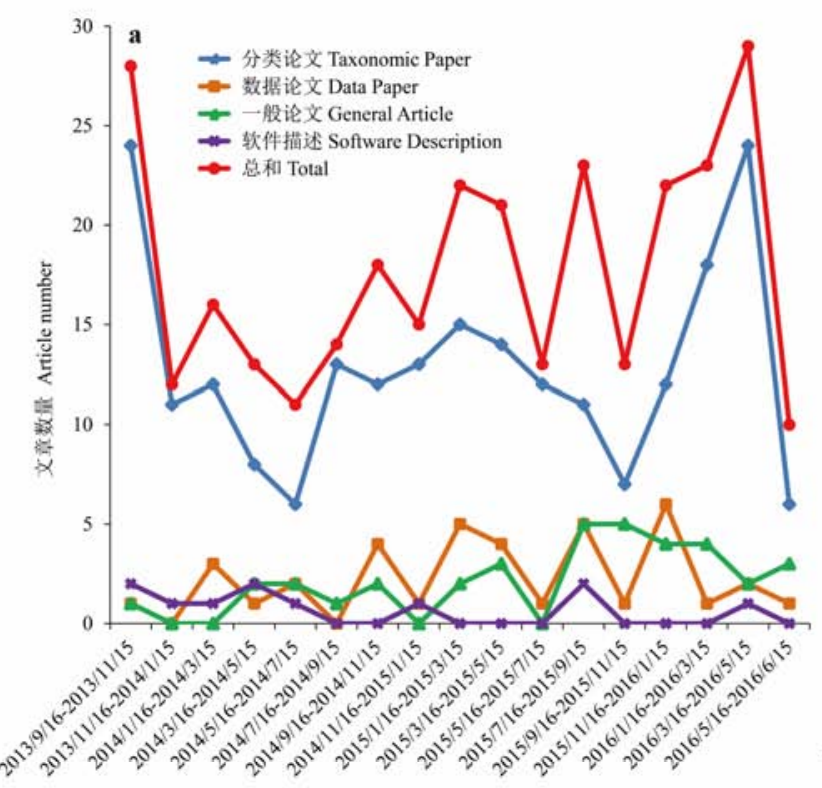

出版日期 Publication date

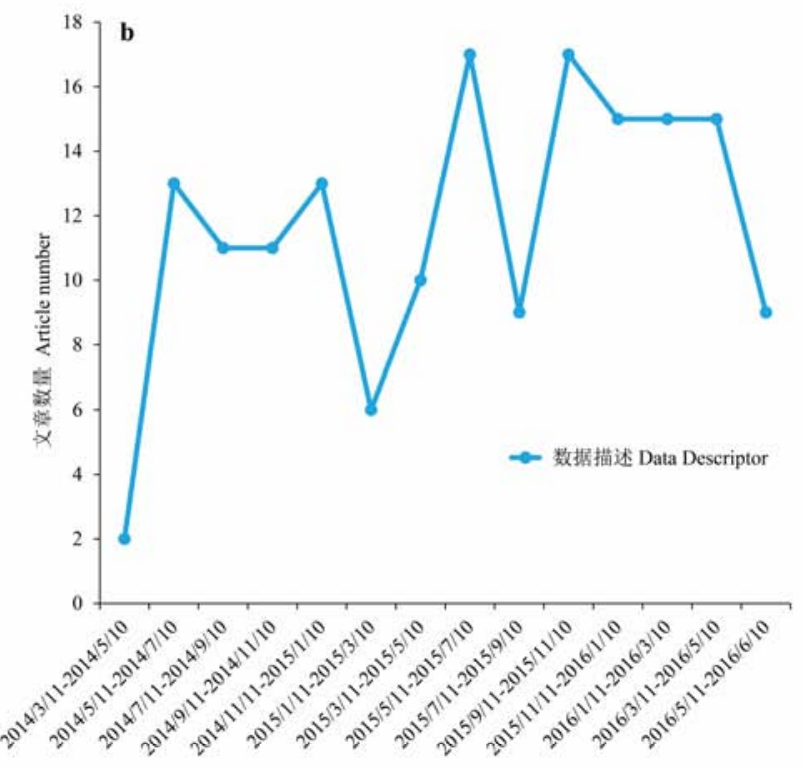

出版日期 Publication date

图1 Biodiversity Data Journal (a)和Scientific Data (b)两本数据期刊自创刊以来的发文量趋势

Fig. 1 Time-series trends of article numbers of two data journals, Biodiversity Data Journal (a) and Scientific Data (b)
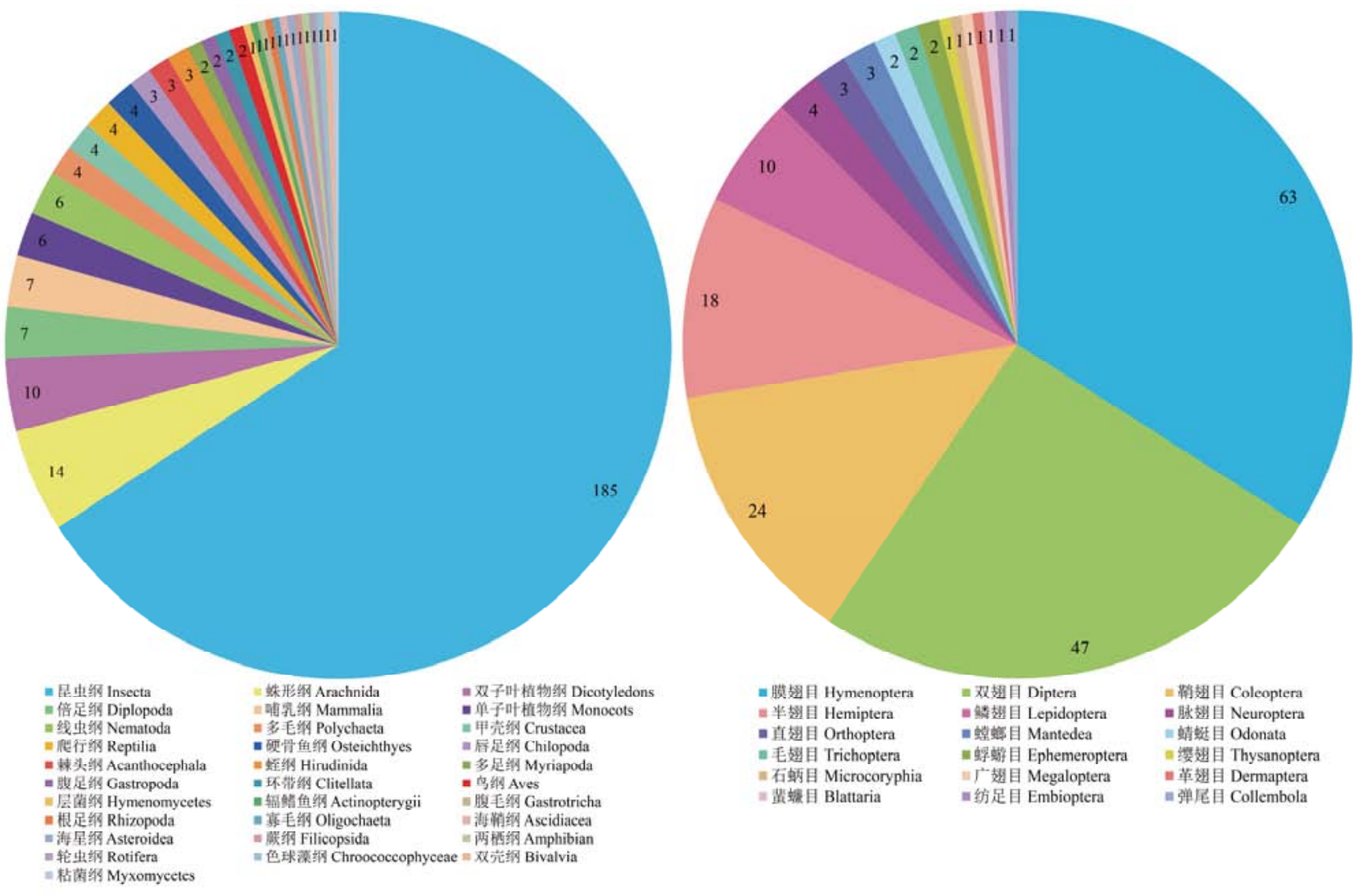

图2 Biodiversity Data Journal的文章所覆盖的生物类群: (a)所有生物类群; (b)昆虫纲。

Fig. 2 The coverage of biological groups in Biodiversity Data Journal papers: (a) All groups; (b) Insecta. 


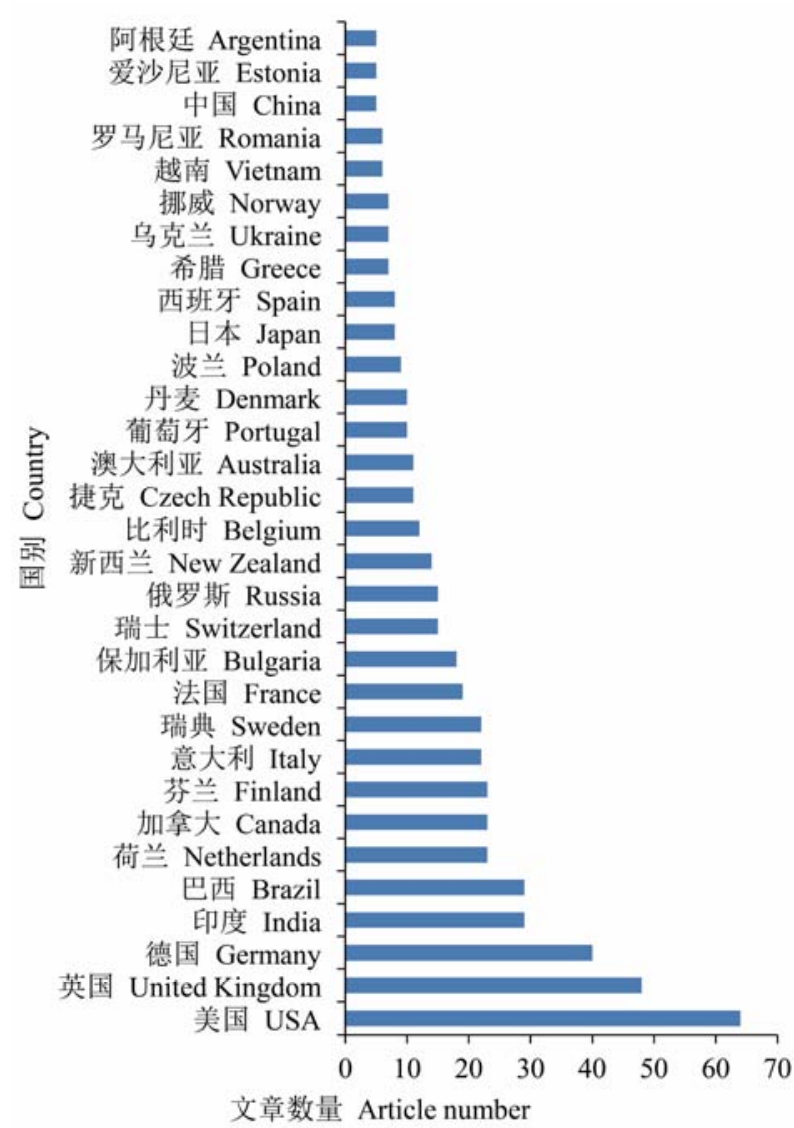

图3 不同国别作者在Biodiversity Data Journal的发文数量 (这里显示了发文数量超过5篇的31个国家或地区, 另有38个 发文数量少于5篇的国家或地区未显示)

Fig. 3 Article numbers published by authors from different countries or regions. The 31 countries or regions with five and more articles are shown, and 38 countries or regions with articles less than five are not shown.

螂目各3篇, 蜻蜓目、蜉蝣目和毛翅目各2篇, 缨翅 目、石蛃目、广翅目、革翅目、蜚蠊目、纺足目、 弹尾目(本文仍将弹尾目归于广义昆虫纲)各1篇。

\subsection{BDJ论文作者国别}

经统计, BDJ文章的作者来自69个国家或地区。 发文量前10位依次是美国64篇、英国48篇、德国40 篇、印度29篇、巴西29篇、荷兰23篇、加拿大 23 篇、 芬兰23篇、意大利22篇、瑞典22篇(图3)。另外法国、 保加利亚、瑞士、俄罗斯、新西兰、比利时、捷克、 澳大利亚、葡萄牙、丹麦等国家的发文数量均在 10 篇以上。这些国家中, 经济和科技发达国家占大多 数。涉及中国研究者的论文共 5 篇, 其中中国研究者 为主要作者的 2 篇, 为合作作者的 3 篇; 从内容来看, 一篇报道石蜈蚣科 1 新种, 一篇报道蝶角蛉科 2 新记
录种，3篇涉及膜翅目部分类群的物种名录和物种 鉴定。

\subsection{BDJ和SD论文汶览量和被引用次数}

两本期刊文章汶览量的分布如图4所示。BDJ 发文数量较多的4类文章(Taxonomic Paper, Data Paper, General Article, Software Description)汶览量 平均为 1,189 次。分别来看, Taxonomic Paper汶览量 平均1,065次; Data Paper平均1,177次; General Article平均1,221次; Software Description平均2,912次。 总体而言, 涉及生物多样性和生态学科学问题讨论 的General Article和涉及生物多样性信息学软件的 Software Description汶览量普遍较高, 其中一篇软 件类文章的汶览量达到近 10,000 次, 反映出读者对 于软件的关注度较高。相较而言, SD文章平均汶览 量较BDJ高, 所发表的163篇Data Descriptor的浏览 量平均为 5,741 次, 其中 23 篇文章汶览量大于 10,000 次, 更有5篇文章大于 20,000 次。对汶览量突出的SD 论文内容进行分析发现，这些论文均报道了数据量 大的全球性数据集, 比如全球综合干旱监测和预测 系统、埃博拉病毒在人类传播暴发的地理综合数据 库、湖面温度全球数据集、病原体一宿主物种关系全 球分布数据集、全球城市化历史数据集等。相关性 检验显示, 对于这两本创刊时间并不长的数据期刊 来说, 其文章浏览量与发表时长总体上具有一定的 正相关关系, 即发表时间越长, 汶览量可能越大。

SD所发表的163篇Data Descriptor文章中, 有 103篇(63.2\%)被引用, 来自CrossRef和Scopus的引 用量分布如表1所示, CrossRef和Scopus数据反映的 趋势总体一致。据统计, 103篇文章共被引用515次, 篇均被引 5 次; 引用排名前 $30 \%$ 的文章贡献了约

表1 Scientific Data文章的被引次数分布。表中“文章数量” 表示在某个引用量区间内的文章数量。

Table 1 The citation numbers of Scientific Data papers. 'Article numbers' in this table means the numbers of articles within certain citation ranges

\begin{tabular}{llll}
\hline $\begin{array}{l}\text { CrossRef引用量 } \\
\text { CrossRef citations }\end{array}$ & $\begin{array}{l}\text { 文章数量 } \\
\text { Article } \\
\text { numbers }\end{array}$ & $\begin{array}{l}\text { Scopus引用量 } \\
\text { Scopus citations }\end{array}$ & $\begin{array}{l}\text { 文章数量 } \\
\text { Article } \\
\text { numbers }\end{array}$ \\
\hline $0-5$ & 77 & $0-5$ & 53 \\
$5-10$ & 10 & $5-10$ & 14 \\
$10-15$ & 4 & $10-15$ & 5 \\
$15-20$ & 4 & $15-20$ & 2 \\
$20-25$ & 1 & $20-25$ & 2 \\
$25-30$ & 2 & $25-30$ & 1 \\
\hline
\end{tabular}



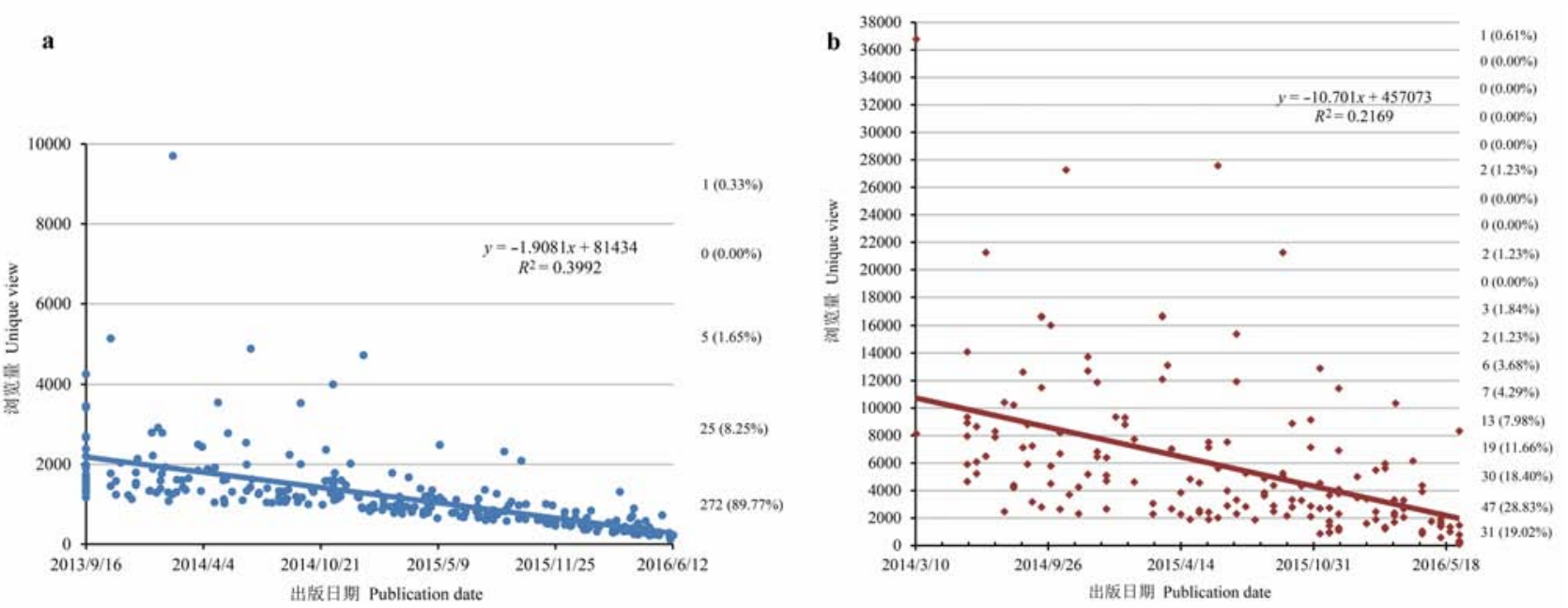

图4 Biodiversity Data Journal (a)四类文章(Taxonomic Paper, Data Paper, General Article, Software Description)和Scientific Data (b) Data Descriptor文章的汶览量

Fig. 4 The unique view numbers of four types of articles (Taxonomic Paper, Data Paper, General Article, Software Description) in Biodiversity Data Journal (a) and Data Descriptor articles in Scientific Data (b)

$70 \%$ 的引用次数。总体来说, 论文引用数和论文数 量呈指数分布关系，符合期刊论文引用分布的一般 性规律(Chatterjee et al, 2016)。对比分析SD文章的 汶览数和被引次数, 虽然发现部分被引次数高的论 文往往也有较大的浏览量, 但两者之间并无明显的 关联。

\section{3 讨论}

虽然科学数据共享包括生物多样性数据共享 在近几年被广泛关注和推动, 但不同领域、不同地 区研究者的数据共享意识和意愿仍很不均衡且有 待提高(Alsheikh-Ali et al, 2011; Tenopir et al, 2011; Huang et al, 2012; Fane et al, 2016)。生物多样性数据 论文之所以被提出, 核心目的是让研究者能够采用 熟悉的、基于同行评审的学术出版形式, 一方面可 以促进生物多样性数据共享, 另一方面可以应对现 行的以论文为主的科研评价模式。我们对BDJ和SD 的分析发现, 这两本数据期刊自创刊以来的发文量 都呈增长趋势, 说明数据论文这种较新的数据共享 方式正在被越来越多的研究者所接受。除了BDJ和 $\mathrm{SD}$ 等专门发表数据论文的数据期刊, 数据论文这 种形式也越来越被更多学术期刊认可。比如, Faculty of 1000旗下的F1000 Research, BioMed Central 旗下的BMC Research Notes、GigaScience 等发表 “Data Note”, Frontiers旗下期刊Frontiers in Ecology and Evolution和Frontiers in Plant Science等发表 “Data Report”。国内一些相关领域期刊也开设了重 在数据发表的栏目, 比如《生物多样性》的“生物编 目”栏目，《植物生态学报》的“资料论文”栏目。但 总体来看, 国内期刊在数据论文发表数量、数据共 享方式等方面需要提高。

研究发现, 数据论文(基于BDJ的分析)所报道 的生物多样性数据已经覆盖了众多生物类群, 包括 动物界26纲、植物界3纲、真菌界2纲, 暗示不同领 域、不同类群的研究者均开始尝试这种新的发表形 式。然而, 类群的总体覆盖度和均匀度仍需要提高, 比如目前植物和微生物类群数据报告偏少, 不同昆 虫类群的数据发表也不均衡。基于文章内容的分析 也发现, BDJ所发表的部分文章存在数据量过少的 问题。相较而言, SD所发表的文章都为较大数据集。 Huang等(2013)曾讨论过生物多样性数据论文应当 报道多少数据量的问题, 认为虽然数据论文是否值 得发表取决于对数据量、类群的重要性、研究地区 等不同因素的综合判断，但一篇数据论文还是应当 达到一定的数据量才更有价值, 同时发挥激励研究 者共享的作用。

汶览量和被引次数分析说明, 数据论文能够获 得足够的关注和使用。BDJ文章的平均浏览量与同 为Pensoft出版的SCI期刊ZooKeys和PhytoKeys相当 甚至更高。SD文章平均汶览量较高, 可能与该刊为 
综合性数据期刊, 以及由知名度高的自然出版集团 出版有关。截至本文数据采集时间, SD文章的平均 被引次数为 5 次, 已高于很多生物多样性和生态学 领域期刊同时期发表的研究论文。浏览量和被引数 据均表明数据论文有足够的价值以获得相当数量 的使用, 近期的一项调研也说明了研究者对于数据 引用价值的认可(Fane et al, 2016)。对浏览量和被引 次数都很突出的论文数据集进行分析发现, 具有较 广泛意义、数据量大的综合数据集更能引起关注, 这对科学家基于数据论文的数据共享实践有重要 的启示。

数据论文的数量可以在某种程度上反映出不 同国家或地区的研究者对生物多样性数据共享的 态度。分析BDJ文章作者的国别发现, 经济和科技 都较为发达的北美和欧洲地区的研究者更倾向于 共享生物多样性数据。虽然中国是生物多样性大国, 但有中国作者署名的BDJ文章仅为5篇, 而同为生 物多样性大国、经济发展水平处于类似阶段的巴西 和印度的研究者在生物多样性数据论文发表方面 多于中国研究者。这一方面反映了中国研究者对生 物多样性数据论文这种新的数据共享方式尚不了 解, 相关领域的中国期刊可以做些推进工作; 另一 方面反映出中国相关领域的数据共享文化有待普 及。之前有关生物多样性领域科学家对数据共享态 度的一项国际调研(Huang et al, 2012), 以及最近一 份有关科学数据共享的报告(Fane et al, 2016), 均显 示亚洲地区研究者的数据共享意愿较低, 这也可能 与部分亚洲国家普遍采用以SCI论文作为科研评价 的主要指标有关。

对 BDJ和SD两本数据期刊的分析, 为理解生物 多样性数据论文的发表趋势提供了实证数据, 也说 明了数据论文对于生物多样性领域的研究和数据 共享实践具有重要价值。近期, Ecology Letters等期 刊联合发表社论, 呼吁生态进化领域的科学家应该 通过数据共享等增加研究的透明性和可靠性, 并称 将开始实施有关数据共享等的新举措(Parker et al, 2016)。我们建议中国生物多样性领域的研究者和期 刊关注生物多样性论文和生态进化领域期刊有关 数据共享政策的进展, 并更多地践行生物多样性数 据共享。

致谢: 审稿专家和责任编委对本文提出了宝贵的修
改建议，特此致谢！

\section{参考文献}

Alsheikh-Ali AA, Qureshi W, Al-Mallah MH, Loannidis JPA (2011) Public availability of published research data in high-impact journals. PLoS ONE, 6, e24357.

Cassey P, Blackburn TM (2006) Reproducibility and repeatability in ecology. BioScience, 56, 958-959.

Chatterjee A, Ghosh A, Chakrabarti BK (2016) Universality of citation distributions for academic institutions and journals. PLoS ONE, 11, e0146762.

Chavan V, Penev L (2011) The data paper: a mechanism to incentivize data publishing in biodiversity science. BMC Bioinformatics, 12 (Suppl. 15), S2.

Costello MJ, Michener WK, Gahegan M, Zhang ZQ, Bourne PE (2013) Biodiversity data should be published, cited, and peer reviewed. Trends in Ecology \& Evolution, 28, 454-461.

De Wever A, Schmidt-Kloiber A, Gessner MO, Tockner K (2012) Freshwater journals unite to boost primary biodiversity data publication. BioScience, 62, 529-530.

Fane B, Treadway J, Gallagher A, Penny D, Hahnel M (2016) Open season for open data: a survey of researchers. doi: https://dx.doi.org/10.6084/m9.figshare.4036398.

Haddaway N, Pullin A (2013) Evidence-based conservation and evidence-informedpolicy: a response to Adams \& Sandbrook. Oryx, 47, 336-338.

Hampton SE, Strasser CA, Tewksbury JJ, Gram WK, Budden AE, Batcheller AL, Duke CS, Porter JH (2013) Big data and the future of ecology. Frontiers in Ecology and the Environment, 11, 156-162.

Huang XL, Hawkins BA, Lei FM, Miller GL, Favret C, Zhang RL, Qiao GX (2012) Willing or unwilling to share primary biodiversity data: results and implications of an international survey. Conservation Letters, 5, 399-406.

Huang XL, Hawkins BA, Qiao GX (2013) Biodiversity data sharing: will peer-reviewed data papers work? BioScience, 63, 5-6.

Huang XL, Qiao GX (2011) Biodiversity databases should gain support from journals. Trends in Ecology \& Evolution, 26, 377-378.

Huang XL, Qiao GX (2014) Sharing and publishing of biodiversity data: recent trends and future suggestions. Biodiversity Science, 22, 293-301. (in Chinese with English abstract) [黄晓磊, 乔格侠 (2014) 生物多样性数据共享和 发表: 进展和建议. 生物多样性, 22, 293-301.]

Michener WK, Jones MB (2012) Ecoinformatics: supporting ecology as a data-intensive science. Trends in Ecology \& Evolution, 27, 85-93.

Parker TH, Nakagawa S, Gurevitch J, IIEE Workshop Participants (2016) Promoting transparency in evolutionary biology and ecology. Ecology Letters, 19, 726-728.

Pullin AS, Salafsky N (2010) Save the whales? Save the rainforest? Save the data! Conservation Biology, 24, 915-917.

Reichman OJ, Jones MB, Schildhauer MP (2011) Challenges 
and opportunities of open data in Ecology. Science, 331, 703-705.

Ryan MJ (2011) Replication in field biology: the case of the frog-eating bat. Science, 334, 1229-1230.

Shapiro JT, Báldi A (2012) Lost locations and the (ir)repeatability of ecological studies. Frontiers in Ecology and the Environment, 10, 235-236.
Tenopir C, Allard S, Douglass K, Aydinoglu AU, Wu L, Read E, Manoff M, Frame M (2011) Data sharing by scientists: practices and perceptions. PLoS ONE, 6, e21101.

Vines TH, Albert AYK, Andrew RL, Débarre F, Bock DG, Franklin MT, Gilbert KJ, Moore JS, Renaut S, Rennison DJ (2014) The availability of research data declines rapidly with article age. Current Biology, 24, 94-97.

(责任编委: 严岳鸿 责任编辑: 黄祥忠)

\section{附录 Supplementary Material}

附录1 Biodiversity Data Journal和Scientific Data两本数据期刊截止2016年6月17日的文献信息

Appendix 1 Bibliographical information of the two data journals, Biodiversity Data Journal and Scientific Data, by 17 June 2016 http://www.biodiversity-science.net/fileup/PDF/2016325-1.xls 
附录1 Biodiversity Data Journal和Scientific Data两本数据期刊截止2016年6月17日的文献信息

Appendix 1 Bibliographical information of the two data journals, Biodiversity Data Journal and Scientific Data, by 17 June 2016

\section{Publication}

date

\section{Article type}

Unique view Biological group

2013/9/16 Editorial $\quad 5323$

2013/9/16 Taxonomic Paper 2206

2013/9/16 Taxonomic Paper 1524

2013/9/16 Taxonomic Paper 2666

2013/9/16 Taxonomic Paper 4255

2013/9/16

Interactive Key

5337

$2013 / 9 / 16$

General Article

3466

2013/9/16

Data Paper

2704

Software

2013/9/16

Description

1991

2013/9/16

Software

Description

2013/9/16

Taxonomic Paper 1695

2013/9/16

2013/9/16

2013/9/16

2013/9/16
Taxonomic Paper 1720

Taxonomic Paper 2386

Taxonomic Paper 1294

Taxonomic Paper 1288
Diplopoda,Polydesmida

Hymenoptera: Platygastridae s.l.,Scelioninae

Balistidae

(Arachnida,Araneae) and

(Insecta, Hymenoptera, Ichneumonidae, Ephialtini)

\section{Plantae,Cyperaceae}

Echinorhynchus

polychaetes (Annelida)

spider

Coleoptera,Scarabaeidae

Araneae

Hemiptera:Triozidae

Hemiptera:Cicadellidae
Germany、Belgium

United Kingdom

\section{Country/Region}

United Kingdom、Bulgaria、

Netherlands、Germany、France、

USA、Czech Republic、Switzerland

Russia、Bulgaria

USA、Australia、 China

USA

Netherlands

USA

United Kingdom

Greece、Italy

Slovenia、 Liechtenstein、

Switzerland、USA

Russia

Bulgaria、Macedonia、Canada、

New Zealand

New Zealand

\section{Paper content}

\author{
新种（1种）+新记录 \\ 物种名录 $(18$ 个 $)+$ 分布 \\ 新种（1种） \\ 用DNA条形码匹配蜘蛛和寄生蜂 \\ 用一种新的工具- - The Carices \\ Interactive Visual Identification \\ Key (CIVIK)识别北美的苔属植物 \\ 鱼类寄生虫一鱼棘头虫形态变异 \\ 在希腊和意大利（地中海）中沿 \\ 海带的14个采集地采集的一组多 \\ 毛类数据集 \\ 软件 (BioCASe监控服务-一一种 \\ 通过分布式数据网络监测进展和 \\ 数据质量的工具) \\ 软件--EXIF Custom \\ 蜘蛛多样性永久保存 \\ 圣甲虫多样性, 物种清单+分布 \\ 蜘蛛多样性及分布 \\ 新记录 (1种) \\ 新记录 (1种)
}


李俊洁, 黄晓否. 生物多样性数据论文发表趋势分析. 生物多样性, 2016, 24 (12)：1317- 1324. ht t p: //www. bi odi ver si ty- sci ence. net /CN/10. 17520/bi ods. 2016325

\begin{tabular}{|c|c|c|}
\hline 2013/9/16 & Taxonomic Paper & 196 \\
\hline 2013/9/16 & Taxonomic Paper & 141 \\
\hline 2013/9/16 & Taxonomic Paper & 16 \\
\hline 2013/9/16 & Taxonomic Paper & 11 \\
\hline 2013/9/16 & Taxonomic Paper & 16 \\
\hline 2013/9/16 & Taxonomic Paper & \\
\hline 2013/9/16 & Taxonomic Paper & \\
\hline 2013/9/16 & Taxonomic Paper & 19 \\
\hline 2013/9/16 & Taxonomic Paper & 134 \\
\hline $2013 / 10 / 28$ & Taxonomic Paper & \\
\hline $2013 / 10 / 28$ & Taxonomic Paper & \\
\hline $2013 / 10 / 28$ & Taxonomic Paper & \\
\hline 2013/11/6 & Taxonomic Paper & \\
\hline $2013 / 11 / 6$ & Taxonomic Paper & 15 \\
\hline $2013 / 11 / 14$ & Taxonomic Paper & \\
\hline $2013 / 11 / 27$ & Taxonomic Paper & \\
\hline $2013 / 12 / 3$ & Taxonomic Paper & \\
\hline $2013 / 12 / 10$ & Taxonomic Paper & \\
\hline $2013 / 12 / 10$ & Taxonomic Paper & \\
\hline $2013 / 12 / 10$ & Taxonomic Paper & \\
\hline
\end{tabular}

Coleoptera:Staphylinidae:Psel

aphinae

Bulgaria

Neuroptera:Hemerobiidae Canada

Hymenoptera,Platygastridae India

Diplopoda,Glomerida,Glomer idellidae

ilsecla.meilipleia.cilauviue Portugal

Ephemeroptera,Leptophlebii

dae

Finland

Diptera:Sciaroidea:Lygistorrhi United Kingdom、Hungary、

nidae

Sweden

Hymenoptera:Pteromalidae

Hymenoptera:Encyrtidae

Annelida:Clitellata

New Zealand

Diptera:Dolichopodidae

Italy

Finland

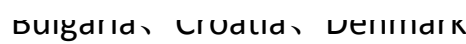

Chilopoda:Lithobiomorpha:Lit China、Germany、Belgium、

hobiidae

France、Italy、 United Kingdom、

Heteroptera: Reduviidae New Zealand

Diplopoda,Glomerida,Glomer idae

\begin{tabular}{|c|c|}
\hline Coleoptera:Carabidae & Italy \\
\hline Coleoptera,Scarabaeidae & Russia \\
\hline 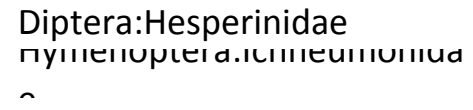 & $\begin{array}{l}\text { Estonia } \\
\text { Sweden }\end{array}$ \\
\hline 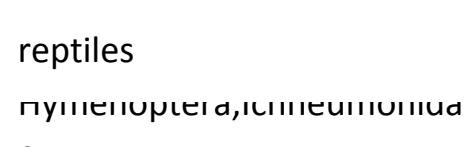 & $\begin{array}{l}\text { Vietnam、Germany、Lao People's } \\
\text { Democratic Republic } \\
\text { Ukraine }\end{array}$ \\
\hline
\end{tabular}

新种（1种）

气候变化的1种潜在指示物种 更改1个物种的名字，即新异名+ 分布

新记录（1种）

新记录（1种）

新记录（2种）

新种（1种）

先前在一地区引进一物种, 后来 消失，第二次在该地区发现同一

新记录（1种）

新记录（2种）

更新芬兰长足虻科名录清单，重 新评估某物种的地位

新种（1种）

新记录（1种）

新种（3种）

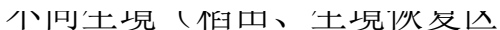
等) 的步甲科昆虫研究+物种名

新种 (4种) +分布

新记录（1种）

新种 (1种)

新记录（4种）

新记录（2种），新异名 
$2014 / 1 / 3$

Taxonomic Paper 1343

$2014 / 1 / 6$

Taxonomic Paper 2793

$2014 / 1 / 8$

2014/1/8

Taxonomic Paper 1889

Software

Description

2217

2014/1/14

2014/1/17

$2014 / 1 / 21$

$2014 / 1 / 21$

$2014 / 1 / 23$

2014/1/24

$2014 / 1 / 29$

$2014 / 2 / 3$

$2014 / 2 / 4$

$2014 / 2 / 10$

$2014 / 2 / 11$

2014/2/14

2014/2/17

$2014 / 2 / 18$

$2014 / 2 / 25$
Taxonomic Paper 1291

Data Paper

2919

Taxonomic Paper 1389

Taxonomic Paper 1592

Taxonomic Paper 1764

Data Paper 2785

Data Paper 1929

Taxonomic Paper 1297

Taxonomic Paper 1078

Taxonomic Paper 1249

Software

Description

9702

Species Inventory 1668

Taxonomic Paper 1304

Taxonomic Paper 1613

Species Inventory 1686
Albania、Denmark

Hymenoptera:Ceraphronoide

a:Megaspilidae

India

Hymenoptera:Braconidae:Mi

crogastrinae

aquatic plants

Mantodea:Mantidae and

Amorphoscelidae

New Zealand、Denmark

Portugal、United Kingdom

United Kingdom

Hymenoptera,Ichneumonida e,Campopleginae

Ukraine

Polychaeta

Basidiomycota,Polyporales

vascular plants

Greece、Italy、Germany

Hungary

Kyrgyzstan、 Finland

Hemiptera:Pseudococcidae

USA

Cameroon、France

Odonata

United Kingdom

Neuroptera:Myrmeleontidae Italy

Coleoptera:Tenebrionidae:All eculinae

New Zealand

Asteiidae

USA

Arachnida:Araneae

\section{United Kingdom}

Hirudinida:Arhynchobdellida:

Erpobdelliformes

Portugal、Finland、Brazil

Hymenoptera:Formicidae

Japan、Russia

Hymenoptera:

Ichneumonidae
新记录（12个分类群），物种名 录+分布

新记录（1属）+新种（1种）

新记录（1种）

更新物种名录

新记录（3种）

an implementation of the Darwin Core Archive (DwC-A) standard

新记录（1属，2种）

数据库 (海洋多毛类)

新记录 (1种)

新记录（4种）+分布区扩散

新记录 (1种)

树种多样性（数据集）

特性数据集（蜻蜓目）

报道罕见物种（4种）+新记录

(1种)

\section{物种继续存在的证据}

新记录（5种）

为低成本的环境监测开源数据记 录器

特有种的空间分布

新记录（1种）

新种（1种）

新记录 (61种), 物种名录+分

布 
李俊洁, 黄晓否. 生物多样性数据论文发表趋势分析. 生物多样性, 2016, 24 (12)：1317- 1324. ht t p: //www. bi odi ver si ty- sci ence. net /CN/10. 17520/bi ods. 2016325

\begin{tabular}{|c|c|c|}
\hline $2014 / 2 / 27$ & Taxonomic Paper & 160 \\
\hline $2014 / 2 / 28$ & Taxonomic Paper & 142 \\
\hline $2014 / 3 / 5$ & Taxonomic Paper & 135 \\
\hline 2014/3/10 & Taxonomic Paper & 16 \\
\hline $2014 / 3 / 26$ & $\begin{array}{l}\text { Software } \\
\text { Description }\end{array}$ & \\
\hline $2014 / 3 / 26$ & Taxonomic Paper & 249 \\
\hline 2014/3/31 & Taxonomic Paper & 133 \\
\hline $2014 / 4 / 2$ & Taxonomic Paper & 243 \\
\hline 2014/4/11 & Taxonomic Paper & 187 \\
\hline 2014/4/11 & Species Inventory & 170 \\
\hline $2014 / 4 / 22$ & General Article & 187 \\
\hline $2014 / 4 / 23$ & Taxonomic Paper & 104 \\
\hline $2014 / 4 / 24$ & General Article & 192 \\
\hline $2014 / 4 / 29$ & $\begin{array}{l}\text { Software } \\
\text { Description }\end{array}$ & \\
\hline $2014 / 5 / 8$ & Taxonomic Paper & 160 \\
\hline $2014 / 5 / 9$ & Taxonomic Paper & 112 \\
\hline $2014 / 5 / 10$ & Data Paper & 10 \\
\hline 2014/5/13 & Taxonomic Paper & \\
\hline
\end{tabular}

\author{
Hymenoptera:Braconidae \\ Potamogetonaceae \\ Canada \\ Hymenoptera, Ichneumonida \\ e \\ Insecta:Diptera:Mydidae:Sylle \\ gomydinae \\ New Zealand、Japan、Thailand \\ Sweden、Netherlands \\ USA
}

\section{United Kingdom}

iveciler lallus、 swriler Iallu、

Araneae,Symphytognathidae

Malaysia、Denmark、USA、Czech

Republic、United Kingdom、

Elateridae Italy

Diptera:Ditomyiidae,Keroplati

dae,Bolitophilidae and Finland、Russia

Mycetophilidae

Myriapoda:Diplopoda,Chilop oda

Germany

\section{Coleoptera:Carabidae}

Greece

Coldenia,Colsmannia,Cynoglo ssum, and Omphalodes

Heteroptera:Anthocoridae

Honey bees、Graminoids

New Zealand

USA

USA

\section{fish species}

Hemiptera:Cicadoidea

Australia、Mexico

Portugal

Arecaceae

aquatic monocots

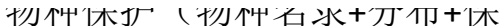

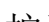

新记录（1种）

新种（1种）, 新记录（1种）, 重新审查1个属

重新回顾物种（物种描述+诊断+ 分布）

软件包（超级树工具包）

新种（1种）

新记录(1种)

两个地方新记录（64种、34种） 、欧洲动物区系新记录（9种）

物种名录+分布, 新记录（9种）

景观异质性对地面甲虫的影响, 物种名录+分布

对 4 个属的观察, 原始文献重新 发表, 翻译

新西兰1个物种的生物学性状、 分布、生物安全现状和历史

蜜蜂为禾草类传粉

一个网站（The Encyclopedia of Life v2, 提供地球生命信息的全 球访问)

物种名录+分布, 新记录（5种) 新记录（1种）

数据集 (同域植物形态类型的土 壤和光照条件)

水生单子叶植物的染色体研究 


\begin{tabular}{|c|c|c|}
\hline $2014 / 5 / 16$ & Taxonomic Paper & 278 \\
\hline $2014 / 5 / 23$ & Taxonomic Paper & \\
\hline 2014/6/10 & Data Paper & \\
\hline 2014/6/16 & General Article & \\
\hline 2014/6/17 & General Article & 1 \\
\hline 2014/6/17 & Taxonomic Paper & \\
\hline $2014 / 6 / 23$ & Taxonomic Paper & \\
\hline $2014 / 6 / 24$ & $\begin{array}{l}\text { Software } \\
\text { Description }\end{array}$ & \\
\hline $2014 / 6 / 26$ & Taxonomic Paper & \\
\hline $2014 / 7 / 7$ & Data Paper & \\
\hline $2014 / 7 / 8$ & Taxonomic Paper & \\
\hline $2014 / 7 / 21$ & Taxonomic Paper & \\
\hline $2014 / 7 / 22$ & Taxonomic Paper & \\
\hline $2014 / 7 / 30$ & Taxonomic Paper & \\
\hline $2014 / 8 / 11$ & General Article & \\
\hline $2014 / 8 / 11$ & Taxonomic Paper & \\
\hline 2014/8/12 & Taxonomic Paper & \\
\hline $2014 / 8 / 18$ & Taxonomic Paper & \\
\hline $2014 / 8 / 19$ & Taxonomic Paper & \\
\hline $2014 / 8 / 22$ & Taxonomic Paper & \\
\hline
\end{tabular}

USA

$\begin{array}{ll}\text { Coleoptera,Coccinellidae } & \text { India } \\ \text { vascular plants } & \text { Belgium }\end{array}$

Netherlands、Bulgaria、Italy、

United Kingdom、USA、Belgium、生物多样性数据（作为一种资源 Germany、New Zealand、

Switzerland、Canada、Finland United Kingdom

Hymenoptera

Hymenoptera: Evanioidea

Hymenoptera:Apoidea

United Kingdom

Austria

USA

Diptera:Calliphoridae

India

Australia

Crustacea,Brachyura,Gecarci

nidae

Bolivia

Hymenoptera:Braconidae:Aly siinae

Spain、Russia

Saproxylic beetles

Italy

Lamiaceae

United Kingdom

USA

Nematoda,Dorylaimida,Belon diridae

Hymenoptera:Formicidae

Vietnam、Germany、Spain

Diptera: Ephydridae

India

Nematodes

USA

Sweden

Hymenoptera:Formicidae India
植物区系库存, 物种名录+分布 重新描述物种（1种）, 新记录 (1种）, 命名法

维管植物的分布

生物多样性数据（作为一种资源
和服务）

膜翅目昆虫清单

物种清单

物种组成+第1份物种清单

信息的虚拟平台)

新记录（1种）

数据集 (出版新的澳大利亚昆虫 的研究趋势)

陆地蟹的生态系统, 新记录 (9

种）

物种多样性

Saproxylic甲虫 (物种名录+分布+ 注释)

新种（1种）

蓝花颜色的使用模式代表生活百

科全书内容提供商

新记录（3属）

第一次描述工蚁

特有种新的岛屿记录（4种）

更新北极陆地和淡水栖息地的线 虫列表

首次描述喜马拉雅特有种雄蚁, 重新描述雌蚁和蚁后
Symbiota软件（基于生物多样性 
李俊洁, 黄晓否. 生物多样性数据论文发表趋势分析. 生物多样性, 2016, 24 (12)：1317- 1324 ht t p: // www. bi odi ver si ty- sci ence. net /CN/10. 17520/bi ods. 2016325

\begin{tabular}{|c|c|c|c|c|c|}
\hline $2014 / 8 / 25$ & Taxonomic Paper & 1140 & $\begin{array}{l}\text { Coleoptera:Coccinellidae:Coc } \\
\text { cinellinae }\end{array}$ & India & 新种（1种） \\
\hline 2014/8/27 & Taxonomic Paper & 1365 & $\begin{array}{l}\text { Hymenoptera: } \\
\text { Ceraphronoidea }\end{array}$ & United Kingdom & 物种清单 \\
\hline 2014/8/29 & Taxonomic Paper & 2240 & $\begin{array}{l}\text { Hymenoptera - Sawflies, ' } \\
\text { Symphyta' }\end{array}$ & Germany、United Kingdom & 物种清单 \\
\hline 2014/9/9 & Taxonomic Paper & 1193 & Diptera,Keroplatidae & Finland & 新种（1种） \\
\hline 2014/9/12 & Taxonomic Paper & 1050 & $\begin{array}{l}\text { Hymenoptera:Apidae: } \\
\text { Eucerini }\end{array}$ & Brazil & 雄性蜜蜂聚集睡觉（2属） \\
\hline 2014/9/17 & General Article & 3532 & & $\begin{array}{l}\text { Finland、Netherlands、Switzerland } \\
\text { 、Denmark、Philippines、France、 } \\
\text { Poland、Slovakia、Germany、 } \\
\text { Bulgaria }\end{array}$ & 数据库（欧洲动物区系） \\
\hline $2014 / 9 / 17$ & Data Paper & 2002 & Helminths & $\begin{array}{l}\text { United Kingdom、Bulgaria、Czech } \\
\text { Republic、Norway、Poland、USA、 } \\
\text { France、Denmark、Netherlands }\end{array}$ & 欧洲动物区系数据库中的寄生虫 \\
\hline 2014/9/19 & Taxonomic Paper & 1168 & $\begin{array}{l}\text { Lepidoptera:Geometridae,Ge } \\
\text { ometrinae,Lophochoristini }\end{array}$ & Estonia & 新种（2种） \\
\hline $2014 / 9 / 30$ & Taxonomic Paper & 1000 & Diptera:Therevidae & Australia & 新种（1种） \\
\hline $2014 / 10 / 6$ & Taxonomic Paper & 1374 & Reptilia,Gekkonidae & $\begin{array}{l}\text { Spain、Portugal、Czech Republic、 } \\
\text { Italy }\end{array}$ & 新记录（2种），更新分布图 \\
\hline 2014/10/9 & Taxonomic Paper & 1305 & Trichoptera & Brazil & $\begin{array}{l}\text { 第2份物种清单（物种名录+分布 } \\
\text { +注释） }\end{array}$ \\
\hline $2014 / 10 / 24$ & Taxonomic Paper & 988 & $\begin{array}{l}\text { Staphylinidae:Pselaphinae:Fa } \\
\text { ronitae }\end{array}$ & New Zealand & 物种额外记录（1种） \\
\hline 2014/10/29 & Taxonomic Paper & 1582 & Hymenoptera:Braconidae & Canada、Bulgaria & $\begin{array}{l}\text { 简化使用生命的条码数据系统 } \\
\text { (BOLD) 中的样本数据来记录物 } \\
\text { 种分布 }\end{array}$ \\
\hline 2014/10/30 & Data Paper & 2364 & Amphibians & France、Germany & 数据库（两栖动物生活史特性） \\
\hline $2014 / 11 / 5$ & Data Paper & 1587 & $\begin{array}{l}\text { Arachnida:Opiliones:Laniator } \\
\text { es:Travunioidea and } \\
\text { Triaenonychoidea }\end{array}$ & Brazil & 世界物种清单 \\
\hline
\end{tabular}


李俊洁, 黄晓否. 生物多样性数据论文发表趋势分析. 生物多样性, 2016, 24 (12)：1317- 1324. ht t p: //www. bi odi ver si ty- sci ence. net /CN/10. 17520/bi ods. 2016325

2014/11/7

Taxonomic Paper 1273

General Article $\quad 4001$

2014/11/11

Taxonomic Paper 1608

$2014 / 11 / 12$

$2014 / 11 / 12$

2014/11/12

$2014 / 11 / 13$

Taxonomic Paper 1102

$2014 / 11 / 14$

Taxonomic Paper

1243

$2014 / 11 / 14$

Data Paper

1782

$2014 / 11 / 17$

Taxonomic Paper 1152

$2014 / 11 / 18$

Taxonomic Paper 1132

2014/11/20 Taxonomic Paper 1290

2014/11/24

$2014 / 11 / 25$

$2014 / 12 / 3$

2014/12/11

$2014 / 12 / 23$

$2014 / 12 / 25$

$2014 / 12 / 25$

$2014 / 12 / 30$

$2014 / 12 / 31$

Taxonomic Paper 1196

Taxonomic Paper 1598

Taxonomic Paper 1480

Software

2018

Taxonomic Paper 1187

Taxonomic Paper 1166

Taxonomic Paper 929

Taxonomic Paper 894

$2015 / 1 / 2$

Taxonomic Paper 4732
Description

Data Paper 1204 fish

apan

USA、Germany、Australia

Diptera:Phoridae

Coleoptera:Coccinellidae

Insecta:Mantodea

USA

Hymenoptera:Braconidae:Mi crogastrinae

Diptera: Milichiidae and

Hymenoptera: Formicidae:

Polyrhachis

Annelida: Hirudinea:

Acanthobdellea and

Branchiobdellea

Diptera,Sciaridae

Trichoptera:Limnephilidae

Chiroptera:Hipposideridae

Diptera:Tachinidae

Insecta:Lepidoptera

Diptera,Limoniidae

Rodentia:Diatomyidae

Arachnida,Opiliones

Diptera:Tipulidae

Insecta:Hemiptera:Cicadellid

e

Insecta:Diptera: Phoridae Republic

Italy Slovenia、Finland

Netherlands

Canada、Germany
Kosovo
India
Canada、USA
Brazil
Finland

Finland

India

Vietnam

France

Lithuania

Brazil
Leguminosae:Papilionoideae

比较预测的物种丰富度和实际调

查的物种丰富度

通过谷歌分析揭示植物多样性数

据的访问趋势

新种（1种),新的物种描述方法

新种 (1种)

新记录（2种），1个更新的物种

名录

新记录（1属），新种（2种）

Malaysia、 United Kingdom、Czech

新记录 (叶蝇科+蚁属)

Germany、Sweden、Italy、United

Kingdom、Finland、Netherlands
数据库（欧洲动物区系）

新种（1种）

新记录 (1属)

分类笔记, 分布区扩展, 物种描 述（1种，特有种）

新种 (1种)

蝴蝶清单

新种（1种），DNA条形码

网络服务 (生物多样性数据自动

化工作流程）

新种（1种）

物种分布及栖息地（1种）

数据库 (物种发生记录)

物种次异名（1种）

物种描述（1种, 雌性, 强调生

殖结构)

物种行为 (蚤蝇、蚂蚁) 
李俊洁, 黄晓否. 生物多样性数据论文发表趋势分析. 生物多样性, 2016, 24 (12)：1317- 1324. ht t p: // www. bi odi ver si ty- sci ence. net /CN/10. 17520/bi ods. 2016325

$\begin{array}{lll}\text { 2015/1/12 } & \text { Taxonomic Paper } & 912 \\ \text { 2015/1/13 } & \text { Taxonomic Paper } & 827 \\ \text { 2015/1/16 } & \text { Taxonomic Paper } & 959 \\ \text { 2015/1/19 } & \text { General Article } & 992 \\ \text { 2015/1/20 } & \text { Taxonomic Paper } & 898 \\ \text { 2015/1/21 } & \text { Corrigendum } & 796 \\ \text { 2015/1/21 } & \text { Editorial } & 1061 \\ \text { 2015/1/26 } & \text { Taxonomic Paper } & 1270 \\ \text { 2015/2/3 } & \text { Taxonomic Paper } & 854 \\ \text { 2015/2/5 } & \text { Taxonomic Paper } & 966 \\ \text { 2015/2/5 } & \text { Data Paper } & 1101 \\ \text { 2015/2/16 } & \text { Taxonomic Paper } & 937\end{array}$

$2015 / 2 / 20$

Data Paper

1783

$2015 / 2 / 23$

Data Paper

781

$2015 / 2 / 25$

$2015 / 2 / 27$

$2015 / 2 / 27$

$2015 / 3 / 4$

$2015 / 3 / 5$

$2015 / 3 / 5$
Fish,Crayfish,

Macroinvertebrates

Amoebozoa:Arcellinida

USA

Bulgaria

Chiroptera

Gastropoda

spider

Teleostei:Beryciformes:

\section{holocentrid}

Insecta:Mantodea

Squamata:Scincidae

Araneae,Tetragnathidae

Diptera: Brachycera

coniferous trees,

Lepidoptera: Notodontidae

Pteridophyta

Vascular plant

Polychaeta,Annelida

Insecta,Coleoptera

Fabaceae

Insecta:Diptera:Asilidae

India

Brazil

Bulgaria

Slovenia、 Liechtenstein、

Switzerland、USA

Netherlands、Switzerland、Bulgaria

USA

Brazil

Vietnam、Germany

Colombia

India、 United Kingdom

Denmark、Netherlands、United

Kingdom、Russia、Poland、

Switzerland、Sweden、Germany、

Ukraine、Belgium、Czech Republic 欧洲动物区系

、Hungary、 Norway、Italy、

Ireland、France、Spain、USA、

Singapore、Bulgaria、Finland

France
Brazil
Brazil
Indonesia
France
India
USA

物种清单

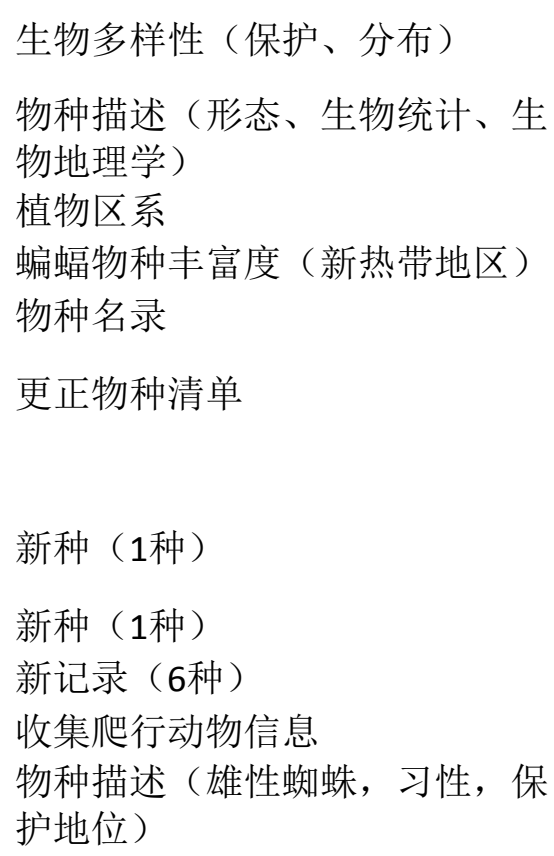

农业景观中针叶树的详尽清单

新记录（13种）

维管植物群落组成

物种丰富度和大量营养素含量

参考库 (甲虫DNA条形码)

重新审查1个属，新种（1种） 
李俊洁, 黄晓否. 生物多样性数据论文发表趋势分析. 生物多样性, 2016, 24 (12)：1317- 1324. ht t p: //www. bi odi ver si ty- sci ence. net /CN/10. 17520/bi ods. 2016325

$2015 / 3 / 6$

$2015 / 3 / 6$

$2015 / 3 / 9$

$2015 / 3 / 9$

$2015 / 3 / 10$

$2015 / 3 / 11$

$2015 / 3 / 17$

$2015 / 3 / 20$

$2015 / 3 / 25$

$2015 / 3 / 26$

$2015 / 3 / 26$

$2015 / 3 / 27$

$2015 / 3 / 30$

$2015 / 4 / 9$

$2015 / 4 / 14$

2015/4/14 Taxonomic Paper 742

2015/4/17

2015/4/17

$2015 / 4 / 22$
Taxonomic Paper 824

Editorial

1074

Data Paper

1203

Taxonomic Paper 874

Taxonomic Paper 885

Taxonomic Paper 762

Taxonomic Paper 929

Taxonomic Paper 942

Taxonomic Paper 806

Taxonomic Paper 838

Taxonomic Paper 808

Data Paper

1391

Taxonomic Paper 783

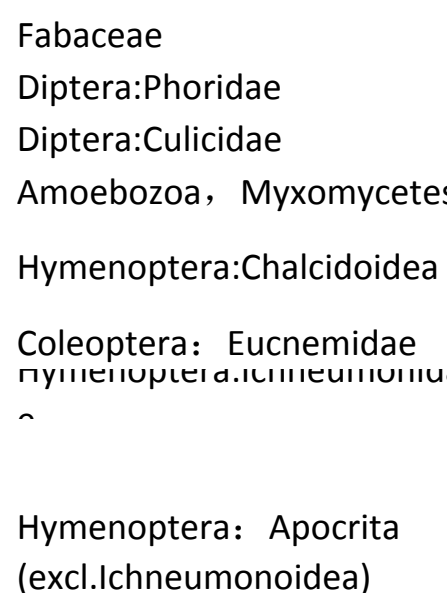

(excl.Ichneumonoidea)

\section{Diptera:Tachinidae}

Coleoptera:Buprestidae

Araneae:Tetragnathidae

Hymenoptera:Formicidae

Diptera:Ephydridae

Coleoptera (Elateriformia,

Scarabaeiformia,

Staphyliniformia and

superfamily Curculionoidea )

Insecta:Coleoptera:Staphylini

dae

Hemiptera:Heteroptera:Gerr omorpha \&Nepomorpha

India
USA
Germany
Finland
India

Finland

Sweden

Romania、United Kingdom、Serbia

、Ukraine、Sweden、Italy、Austria

、Romania、USA、Czech Republic 欧洲动物区系

、Belgium、Estonia、Germany、

Netherlands、Finland

Canada、USA

Bolivia

India

India

Finland、Poland

Italy Spain、Australia、Sweden、

Czech Republic、Switzerland

Poland、Austria、Russia、France、

Germany、United Kingdom、

Netherlands、USA、Finland

\section{USA}

Brazil

USA

Raphidioptera,Megaloptera,N Austria、Italy、Netherlands

europtera

Finland

Diptera:Simuliidae

Turkey
新种（1种）

雌性行为

更新列表

新种 (6种)

新记录 (1种), 新的分布记录

(一些物种)

新记录（9属）

新种、新记录（1种）

新种（7种）

新记录（2种）

缩小物种名和新异名之间的差距 蚂蚁的分类和分布 (1种)

物种名录+分布, 新记录（4种）

网络服务（欧洲动物区系：甲虫 类)

重新审查1个属，新种（1种）

物种名录 (43个) +分布, 新记 录（11种）

网络服务（欧洲动物区系：脉翅 总目）

物种名录（18个），新记录（1 种） 
李俊洁, 黄晓否. 生物多样性数据论文发表趋势分析. 生物多样性, 2016, 24 (12)：1317- 1324. ht t p: //www. bi odi ver si ty- sci ence. net /CN/10. 17520/bi ods. 2016325

\begin{tabular}{|c|c|c|c|c|c|}
\hline $2015 / 4 / 22$ & Data Paper & 987 & Boraginaceae,Cynoglosseae & Germany & 数据库（分类群和名字） \\
\hline $2015 / 4 / 24$ & Taxonomic Paper & 1211 & Insecta:Hemiptera & Japan & 物种清单 \\
\hline $2015 / 4 / 27$ & Taxonomic Paper & 932 & $\begin{array}{l}\text { Hirudinida,Arhynchobdellida, } \\
\text { Praobdellidae }\end{array}$ & Japan、Kazakhstan & 新记录（1种），遗传多样性 \\
\hline $2015 / 4 / 27$ & Taxonomic Paper & 1208 & Perciformes,Serranidae & USA & 新种（1种） \\
\hline $2015 / 4 / 29$ & Taxonomic Paper & 1355 & Ostariophysi,Siluriformes & Brazil & 物种清单 \\
\hline $2015 / 5 / 8$ & General Article & 1140 & $\begin{array}{l}\text { Hymenoptera:Apidae:Bombu } \\
\text { s spp. }\end{array}$ & USA & $\begin{array}{l}\text { 物种组成、分布、季节性生物学 } \\
\text { 和寄生物 }\end{array}$ \\
\hline $2015 / 5 / 8$ & Taxonomic Paper & 654 & $\begin{array}{l}\text { Ephemeroptera:Neoephemer } \\
\text { eidae }\end{array}$ & India & 新记录（1种） \\
\hline $2015 / 5 / 12$ & General Article & 1168 & Crustacea:Peracarida & USA & 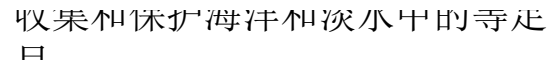 \\
\hline $2015 / 5 / 12$ & General Article & 2486 & & $\begin{array}{l}\text { Netherlands、Switzerland、Bulgaria } \\
\text { 、Germany、Australia、United } \\
\text { Kingdom }\end{array}$ & $\begin{array}{l}\text { 从具前瞻性和遗留分类文献中整 } \\
\text { 合原始数据并使其可视化 }\end{array}$ \\
\hline $2015 / 5 / 18$ & Taxonomic Paper & 1083 & Hymenoptera:Braconidae & Mexico & DNA条形码技术 \\
\hline $2015 / 5 / 19$ & Taxonomic Paper & 1058 & Mammalia:Rodentia & Vietnam & $\begin{array}{l}\text { 新数据（1种, 材料、描述、分 } \\
\text { 布、生态学、保护) }\end{array}$ \\
\hline $2015 / 6 / 2$ & Taxonomic Paper & 779 & Chiroptera,Vespertilionidae & $\begin{array}{l}\text { Brazil、French Guyana、France、 } \\
\text { Switzerland }\end{array}$ & 新记录（1种） \\
\hline $2015 / 6 / 5$ & Taxonomic Paper & 790 & $\begin{array}{l}\text { Chalcidoidea: Encyrtidae } \\
\text { and Mymaridae }\end{array}$ & India & $\begin{array}{l}\text { 增加信息，新记录（分布和寄 } \\
\text { 主，8种，1属） }\end{array}$ \\
\hline $2015 / 6 / 8$ & Taxonomic Paper & 807 & Diptera,Mycetophilidae & Brazil、USA & $\begin{array}{l}\text { 新记录（1属, 菌蚊科幼虫和真 } \\
\text { 菌之间的关系） }\end{array}$ \\
\hline $2015 / 6 / 9$ & Taxonomic Paper & 1111 & $\begin{array}{l}\text { Diplopoda,Glomerida,Glomer } \\
\text { idae }\end{array}$ & Germany、United Kingdom & $\begin{array}{l}\text { 千足虫种群综合研究（条形码技 } \\
\text { 术） }\end{array}$ \\
\hline $2015 / 6 / 16$ & Taxonomic Paper & 692 & $\begin{array}{l}\text { Hemiptera:Reduviidae:Harpa } \\
\text { ctorinae }\end{array}$ & Brazil, Colombia & 新异名, 新组合 \\
\hline 2015/6/19 & Taxonomic Paper & 937 & $\begin{array}{l}\text { Hymenoptera: } \\
\text { Ichneumonidae }\end{array}$ & Italy、Sweden、Germany、Austria & 新记录（55个） \\
\hline $2015 / 6 / 22$ & Taxonomic Paper & 670 & $\begin{array}{l}\text { Coleoptera:Coccinellidae: } \\
\text { Scymnini }\end{array}$ & India & 新种（2种） \\
\hline $2015 / 6 / 25$ & Taxonomic Paper & 786 & Diptera,Nematocera & Finland & 录（12种） \\
\hline
\end{tabular}


李俊洁, 黄晓否. 生物多样性数据论文发表趋势分析. 生物多样性, 2016, 24 (12)：1317- 1324 ht t p: //www. bi odi ver si ty- sci ence. net /CN/10. 17520/bi ods. 2016325

\begin{tabular}{|c|c|c|c|c|c|}
\hline $2015 / 6 / 26$ & Taxonomic Paper & 898 & Sepsidae & Singapore、Switzerland & 新记录（1种），物种清单 \\
\hline 2015/7/13 & Data Paper & 820 & & Spain & 真菌和地衣模式标本目录 \\
\hline 2015/7/15 & Taxonomic Paper & 948 & Pteridaceae & Togo、 France & 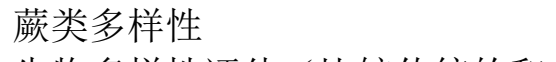 \\
\hline 2015/7/17 & General Article & 848 & & USA & $\begin{array}{l}\text { 生物多样性评估（比较传统的和 } \\
\text { 系统发生多样性指数） }\end{array}$ \\
\hline 2015/7/17 & Taxonomic Paper & 663 & $\begin{array}{l}\text { Euphydryas maturna and } \\
\text { Melampyrum sylvaticum }\end{array}$ & Finland & 寄主植物 \\
\hline 2015/7/17 & Data Paper & 1138 & Mollusca: Bivalvia & Spain、Netherlands、Germany & $\begin{array}{l}\text { 网络服务（欧洲动物区系：双壳 } \\
\text { 纲） }\end{array}$ \\
\hline 2015/7/17 & Taxonomic Paper & 712 & Lepidoptera:Geometridae & Germany & 物种名录+分布 \\
\hline $2015 / 7 / 28$ & $\begin{array}{l}\text { Software } \\
\text { Description }\end{array}$ & 1361 & & Sweden & 一种工具（ignorance maps） \\
\hline $2015 / 7 / 29$ & $\begin{array}{l}\text { Software } \\
\text { Description }\end{array}$ & 598 & & Greece & $\begin{array}{l}\text { 反转RML（研究如何对基于列的 } \\
\text { 数据源执行相反的过程） }\end{array}$ \\
\hline 2015/7/31 & Data Paper & 755 & & Brazil & 树的多样性和森林动态 \\
\hline 2015/7/31 & General Article & 654 & Diptera:Calliphoridae & Belgium & $\begin{array}{l}\text { 初始数据（蛹的发育、寿命、雌 } \\
\text { 体繁殖力） }\end{array}$ \\
\hline 2015/8/10 & Taxonomic Paper & 629 & $\begin{array}{l}\text { Coleoptera,Scarabaeidae,Orp } \\
\text { hninae and Scarabaeinae }\end{array}$ & Russia & 新的位置记录（2种） \\
\hline 2015/8/10 & Taxonomic Paper & 836 & Diptera:Tachinidae & Canada、USA & 新种（3种） \\
\hline 2015/8/11 & Taxonomic Paper & 610 & Indirana & India & 一种濒危青蛙新的分布记录 \\
\hline 2015/8/11 & Taxonomic Paper & 855 & Diptera:Tachinidae & Canada、USA & 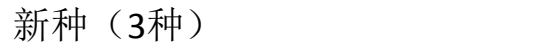 \\
\hline $2015 / 8 / 14$ & General Article & 744 & Triticum & Italy & 小麦育种 \\
\hline 2015/8/14 & Data Paper & 835 & Gastrotricha & $\begin{array}{l}\text { Italy、France、Poland, } \\
\text { Netherlands、Germany }\end{array}$ & $\begin{array}{l}\text { 网络服务（欧洲动物区系: 腹毛 } \\
\text { 动物门) }\end{array}$ \\
\hline $2015 / 8 / 17$ & General Article & 1264 & millipede & USA & $\begin{array}{l}\text { 一种方法（大的千足虫的收集、 } \\
\text { 管理和遗传分析保护） }\end{array}$ \\
\hline 2015/8/18 & General Article & 737 & $\begin{array}{l}\text { Chiroptera,Vespertilionidae } \\
\text { Myotinae }\end{array}$ & Brazil、USA、Argentina & 分布范围扩大 \\
\hline $2015 / 8 / 21$ & Taxonomic Paper & 800 & Diptera:Limoniidae & Romania & 新种(1种），新记录（8种） \\
\hline
\end{tabular}




$\begin{array}{lll}\text { 2015/8/31 } & \text { Taxonomic Paper } & 821 \\ \text { 2015/9/2 } & \text { Data Paper } & 870 \\ & & \\ \text { 2015/9/3 } & \text { Taxonomic Paper } & 581 \\ & & \\ \text { 2015/9/7 } & \text { Taxonomic Paper } & 980\end{array}$

2015/9/11

Data Paper

1068

$2015 / 9 / 24$

$2015 / 9 / 24$

General Article 973

Taxonomic Paper 638

$2015 / 9 / 28$

General Article

2088
Canada、 France、Argentina、New Zealand、Dominican Republic、 Germany、Australia、Bhutan、 Namibia、Finland、Bulgaria、

DNA条形码技术（物种鉴定、生 物多样性评估)

Colombia、USA、Mexico、Nepal、 Belarus、Sweden

Hymenoptera:Orussidae

USA

United Kingdom、South Africa

新记录（1种）

Cicada

Sweden

incertae sedis

Turkey、Russia

Araneae: Dysderidae

Annelida - Terrestrial

Oligochaeta(Enchytraeidae and Megadrili), Aphanoneura and Polychaeta

Italy、Netherlands、Germany

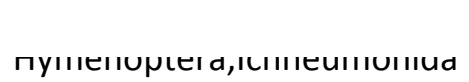

Sweden

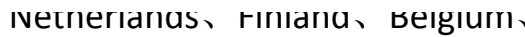

Germany、Norway、 United

Kingdom、Ireland、Denmark、

Greece、New Zealand、France、

Turkey、Romania、Portugal

Albania、Armenia、Austria、

Azerbaijan、Belarus、Czech

Republic、Croatia、Cyprus、Estonia

、Georgia、Hungary、Iceland、

PESI（一个泛欧洲的物种名录基

Israel、Italy Latvia、 Lithuania、

Luxembourg、Macedonia、Malta、

Moldova、Montenegro、Norway、

Poland、Portugal、Russia、Serbia

、Slovakia、Spain、Sweden.

Cusitznrland lllmainn Dillanria
新种（1种）, 重新审查（1属）

新种 (1种)

网络服务（欧洲动物区系：环节 动物门: 寡毛类、Aphanoneura 、多毛类)

鸟类受食的生态学和系统学

物种清单+分布, 新记录 (4种)
础设施） 
李俊洁, 黄晓否. 生物多样性数据论文发表趋势分析. 生物多样性, 2016, 24 (12)：1317- 1324. ht t p: //www. bi odi ver si ty- sci ence. net /CN/10. 17520/bi ods. 2016325

\begin{tabular}{|c|c|c|c|c|}
\hline $2015 / 10 / 5$ & Taxonomic Paper & 625 & Diptera: Heleomyzidae & Canada \\
\hline 2015/10/6 & Taxonomic Paper & 1001 & Insecta:Diptera:Apioceridae & USA、Switzerland \\
\hline 2015/10/7 & Corrigendum & 438 & Diptera:Tachinidae & Canada、USA \\
\hline $2015 / 10 / 26$ & Taxonomic Paper & 605 & $\begin{array}{l}\text { Hymenoptera:Aphelinidae } \\
\text { and Hemiptera: Aleyrodidae }\end{array}$ & United Kingdom、Taiwan \\
\hline $2015 / 10 / 30$ & Taxonomic Paper & 678 & Megachile & USA \\
\hline $2015 / 10 / 30$ & General Article & 610 & Salix & Canada、 United Kingdom \\
\hline 2015/11/9 & General Article & 1008 & $\begin{array}{l}\text { Chiroptera,Vespertilionidae, } \\
\text { Myotinae }\end{array}$ & Brazil \\
\hline 2015/11/10 & Taxonomic Paper & 566 & Amblypygi and Opiliones & Brazil \\
\hline $2015 / 11 / 10$ & Taxonomic Paper & 521 & Nematoda: Hoplolaimidae & Vietnam \\
\hline $2015 / 11 / 13$ & Data Paper & 513 & earthworm & France \\
\hline $2015 / 11 / 13$ & General Article & 553 & & Brazil \\
\hline $2015 / 11 / 16$ & Taxonomic Paper & 554 & Hymenoptera:Formicidae & India \\
\hline $2015 / 11 / 20$ & Taxonomic Paper & 974 & Birds & Portugal、France \\
\hline $2015 / 11 / 23$ & Taxonomic Paper & 528 & Siricidae:Hymenoptera & South Africa、Canada \\
\hline $2015 / 11 / 25$ & Taxonomic Paper & 459 & Hymenoptera,Tenthredinidae & Germany、Estonia \\
\hline $2015 / 11 / 25$ & Taxonomic Paper & 519 & Asteroidea & Belgium \\
\hline $2015 / 11 / 26$ & Taxonomic Paper & 591 & $\begin{array}{l}\text { Diptera:Ceratopogonidae } \\
\text { Coleoptera:Buprestidae,Cara }\end{array}$ & Denmark \\
\hline $2015 / 12 / 10$ & Data Paper & 669 & $\begin{array}{l}\text { bidae,Cerambycidae,Curculio } \\
\text { noidea excluding Scolytinae }\end{array}$ & USA \\
\hline $2015 / 12 / 11$ & Taxonomic Paper & 487 & Ostracoda,Crustacea & Japan \\
\hline 2015/12/11 & General Article & 810 & Butterfly & Malaysia \\
\hline
\end{tabular}

新种（1种）, 修改了新北区一

些关键物种

利用网络资源进行分类

纠正物种名的拼音错误, 新种 (3种)

新种（1种），粉虫和寄生蜂

新的分布记录（1种）+寄主植物

列表

柳树的纬度多样性

鼠耳蝠吃水果的第一个证据

新记录（2种）

新种（1种）

蝶蚂的空间分布模式

虫瑤的寄主植物清单

第一次被证实的记录（1种）,

修订了东洋界主要物种

物种清单+分布, 新种（38种）

新的分布记录（2种）, 交互式

清晰识别关键物种

前蛹和幼虫

物种清单 (更新注册的南极海洋

物种)

新种（3种）

新的州记录 (31种)

新种（1种） + 几乎完整的线粒体 基因组序列

蝴蝶计数 (物种鉴定, DNA条形 码） 


\begin{tabular}{|c|c|c|}
\hline $2015 / 12 / 21$ & Data Paper & 501 \\
\hline $2015 / 12 / 21$ & General Article & 517 \\
\hline 2015/12/21 & Data Paper & 462 \\
\hline $2015 / 12 / 21$ & Taxonomic Paper & 453 \\
\hline $2015 / 12 / 22$ & Taxonomic Paper & 536 \\
\hline $2015 / 12 / 23$ & Taxonomic Paper & 478 \\
\hline $2015 / 12 / 29$ & Data Paper & 658 \\
\hline $2015 / 12 / 30$ & Data Paper & 814 \\
\hline $2016 / 1 / 7$ & General Article & 552 \\
\hline $2016 / 1 / 8$ & Data Paper & 481 \\
\hline 2016/1/8 & Taxonomic Paper & 511 \\
\hline 2016/1/13 & Taxonomic Paper & 363 \\
\hline 2016/1/14 & Corrigendum & 289 \\
\hline 2016/1/15 & General Article & 595 \\
\hline 2016/1/18 & Taxonomic Paper & 661 \\
\hline $2016 / 1 / 18$ & Taxonomic Paper & 365 \\
\hline $2016 / 1 / 20$ & Taxonomic Paper & 473 \\
\hline 2016/1/21 & Taxonomic Paper & 435 \\
\hline 2016/1/21 & Taxonomic Paper & 405 \\
\hline
\end{tabular}

Arachnida: Opiliones:

Laniatores: Samooidea,

Zalmoxoidea and Grassatores

Arachnida: Opiliones:

Laniatores: Samooidea, Brazil、Argentina

Zalmoxoidea and Grassatores

\section{Orthoptera: Gryllotalpidae United Kingdom}

Hymenoptera, Ichneumonida

e,Anomaloninae

Ukraine

Limbodessus

Germany, Indonesia

Diptera:Tachinidae:

\section{Itaplectops}

Canada、 USA

vascular plants

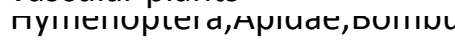

-

Diptera:Tachinidae

Belgium、United Kingdom

Hymenoptera:Chrysididae:

Amiseginae and

Loboscelidiinae

Lepidoptera:Geometridae

USA、Germany

Belgium、United Kingdom

United Kingdom

Germany

Hymenoptera:Pergidae

Uruguay, Germany

Sweden

Arachnida:Araneae

Brazil、Argentina

Diptera, Mycetophilidae

Finland

Neuroptera:Ascalaphidae

China

Nematoda:Oncholaimida:Onc holaimidae

Japan

Hymenoptera:Chalcididae India

Diptera: Trichoceridae

\section{世界物种清单}

世界物种清单（接上一篇）

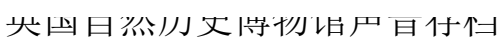
（1科）+三维扫描burrow casts ( 万种)

重新审查1个亚科, 新记录 (8

属, 9种）

新种（2种）

新种 (9种)

普通植物的基础调查

数据库 (大黄蜂)

保存物种颜色（1种）

\section{在线分类数据库}

物种清单

新记录 (1种) +寄主植物+生物

学特性

更改先前的错误, 漏掉一些内容

蜘蛛多样性

新种（4种）, 新记录（3种）,

同义词（1种）

新记录 (2属, 2种)

世界物种清单 (1亚科: 属、物

种、分布, 分类学家和生态学家 的参考列表）

新记录 (20种)

新记录（2种） 


\begin{tabular}{|c|c|c|c|c|c|}
\hline $2016 / 1 / 25$ & Taxonomic Paper & 840 & Echinodermata & $\begin{array}{l}\text { United Kingdom、USA、Australia、 } \\
\text { Norway、Sweden }\end{array}$ & $\begin{array}{l}\text { 形态和基因数据鉴定物种（17 } \\
\text { 种） }\end{array}$ \\
\hline $2016 / 2 / 4$ & Taxonomic Paper & 461 & $\begin{array}{l}\text { Serpentes: Dipsadidae、 } \\
\text { Colubridae、Boidae、 } \\
\text { Viperidae、Anomalepididae } \\
\text { Vlapidae、Typhlopidae }\end{array}$ & Brazil、Sweden & 蛇的多样性（28种） \\
\hline $2016 / 2 / 4$ & General Article & 316 & Echinorhynchus & United Kingdom & 一种分类工具 \\
\hline $2016 / 2 / 8$ & Taxonomic Paper & 439 & $\begin{array}{l}\text { Insecta:Diptera:Phoridae:Mel } \\
\text { aloncha }\end{array}$ & USA & 新种（2种） \\
\hline $2016 / 2 / 8$ & Taxonomic Paper & 450 & Diptera:Anisopodidae & $\begin{array}{l}\text { Romania、Czech Republic、 } \\
\text { Netherlands }\end{array}$ & 新记录（2种） \\
\hline $2016 / 2 / 24$ & Data Paper & 541 & & Australia、Brazil & $\begin{array}{l}\text { 热带雨林植被和植物组成列表, } \\
\text { 分析了干密度和物种多样性 }\end{array}$ \\
\hline $2016 / 3 / 2$ & Taxonomic Paper & 330 & Lilianae & Brazil & 水生和湿地的单子叶植物清单 \\
\hline $2016 / 3 / 2$ & General Article & 291 & Rotifera,Cladocera,Copepoda & Bulgaria & 新记录（3类群） \\
\hline $2016 / 3 / 2$ & Taxonomic Paper & 338 & Tunicata:Ascidiacea & India & 新记录（30种） \\
\hline $2016 / 3 / 7$ & Taxonomic Paper & 375 & Coleoptera,Cerambycidae & Panama & 新记录（2种） \\
\hline $2016 / 3 / 7$ & Taxonomic Paper & 315 & $\begin{array}{l}\text { Crustacea,Decapoda,Achelata } \\
\text {,Palinuridae }\end{array}$ & Indonesia & 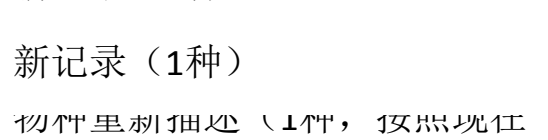 \\
\hline 2016/3/7 & Taxonomic Paper & 350 & Acrididae,Hemiacridinae & Singapore、Malaysia & $\begin{array}{l}\text { 的分类标准描述, 雄性生殖器的 } \\
\text { 复杂性, 证实了亚科物种的位 }\end{array}$ \\
\hline $2016 / 3 / 8$ & Taxonomic Paper & 381 & Hymenoptera:Encyrtidae & India & 新种（2种） \\
\hline $2016 / 3 / 8$ & General Article & 597 & & Germany & 大型城市公墓的生物丰富度 \\
\hline $2016 / 3 / 9$ & Taxonomic Paper & 424 & Lepidoptera:Lycaenidae & Serbia、Croatia & $\begin{array}{l}\text { 新记录 (1种) } \\
\text { 物种鉴定（分子数据, DNA条形 }\end{array}$ \\
\hline 2016/3/9 & Taxonomic Paper & 421 & Braconidae,Euphorinae & Sweden、Netherlands、China & $\begin{array}{l}\text { 码, CO1），古北区物种（2 } \\
\text { 种），东洋区物种（1种） }\end{array}$ \\
\hline 2016/3/10 & Taxonomic Paper & 431 & $\begin{array}{l}\text { Heteroptera:Reduviidae:Eme } \\
\text { sinae }\end{array}$ & India & 新记录（1种） \\
\hline 2016/3/14 & General Article & 1311 & & United Kingdom & $\begin{array}{l}\text { 收集水生昆虫的方法（光照诱 } \\
\text { 捕, LEDs ） }\end{array}$ \\
\hline
\end{tabular}




\begin{tabular}{|c|c|}
\hline 2016/3/21 & Taxonomic Paper \\
\hline $2016 / 3 / 23$ & $\begin{array}{l}\text { Software } \\
\text { Description }\end{array}$ \\
\hline $2016 / 3 / 25$ & Taxonomic Paper \\
\hline $2016 / 3 / 28$ & Taxonomic Paper \\
\hline 2016/4/1 & Taxonomic Paper \\
\hline 2016/4/1 & Taxonomic Paper \\
\hline $2016 / 4 / 4$ & Taxonomic Paper \\
\hline $2016 / 4 / 5$ & Taxonomic Paper \\
\hline $2016 / 4 / 6$ & Data Paper \\
\hline $2016 / 4 / 7$ & Taxonomic Paper \\
\hline $2016 / 4 / 7$ & Taxonomic Paper \\
\hline $2016 / 4 / 8$ & Taxonomic Paper \\
\hline 2016/4/13 & General Article \\
\hline 2016/4/14 & Taxonomic Paper \\
\hline $2016 / 4 / 14$ & Taxonomic Paper \\
\hline 2016/4/15 & Taxonomic Paper \\
\hline 2016/4/15 & Taxonomic Paper \\
\hline $2016 / 4 / 15$ & Taxonomic Paper \\
\hline 2016/4/18 & Taxonomic Paper \\
\hline 2016/4/19 & Taxonomic Paper \\
\hline $2016 / 4 / 21$ & Taxonomic Paper \\
\hline
\end{tabular}

Lepidoptera:Geometridae: Larentiinae

\section{Germany}

Sweden

Coccinellidae

Diptera:Syrphidae

Diptera:Sciaridae

Coleoptera:Carabidae

Cyprinodontiformes:Rivulidae Brazil

vascular plant

cyanobacteria

Hymenoptera:

\section{Apoidea,Chrysidoidea and United Kingdom}

Vespoidea

Nematoda:Diplogastridae India

Diptera, Canacidae,

Procanace

Hymenoptera:Formicidae

Diptera:Phoridae

Hymenoptera:Platygastridae

Poaceae

Hymenoptera:

Proctotrupoidea

Hymenoptera: Trigonaloidea United Kingdom

Hymenoptera:Aphelinidae;

Coleoptera:Curculionidae

Diptera:Tachinidae

United Kingdom、Portugal

Canada、USA

Hymenoptera: Braconidae United Kingdom

\section{物种名录+取食植物}

网络服务 (瑞典生物多样性信息 分析门户)

新记录（1种），新异名

新记录 (1 种)

新种（1种），入侵物种

物种列表

新种（1种）

物快名水(印名法、分伌、注

在线数据库 (蓝藻细菌+寄主)

物种清单（3总科）

新种（1种）

新种（1种）、新记录 (4个)

蚂蚁清单+分类地位+分布, 新记 录 (108个)

新种 (12种)

新记录 (2 种)

物种清单+分布

更新的物种清单+命名法+分布

更新的物种清单（1种）+国家层 面的分布+命名法

\section{寄生蜂和象甲}

新种（2种）

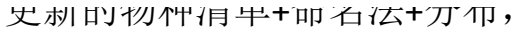

新记录（83个），新异名（1 


$\begin{array}{lll}\text { 2016/4/22 } & \text { Taxonomic Paper } 337 \\ 2016 / 4 / 25 & \text { Taxonomic Paper } 299\end{array}$

$2016 / 4 / 27$

General Article

584

$2016 / 4 / 28$

Taxonomic Paper 281

$2016 / 5 / 3$

$2016 / 5 / 4$

$2016 / 5 / 9$

$2016 / 5 / 13$

$2016 / 5 / 16$

$2016 / 5 / 19$

$2016 / 5 / 20$

$2016 / 5 / 20$

$2016 / 5 / 25$

General Article $\quad 223$

General Article 725

\section{Hymenoptera:}

Diptera:Tachinidae

invertebrate organisms (

Arthropoda, Hexapoda,

Insecta, Lepidoptera,

Odonata, Coleoptera,

Hymenoptera, Diptera,

Hemiptera, Heteroptera,

Orthoptera, Neuroptera,

Psocodea, Thysanoptera,

Blattodea, Embioptera,

Dermaptera, Microcoryphia,

Collembola, Arachnida,

Araneae, Acari, Mollusca,

\section{Gastronoda )}

Hymenoptera:Ichneumonida

\section{e:Tryphoninae}

Aves:Icteridae

Hymenoptera:Braconidae:Rh

ysipolinae

Insecta:Hymenoptera:

"Symphyta"

"Isecla.neImpleid.neleiuple

$m$

Insecta:Hemiptera:

Heteroptera

Myriapoda: Chilopoda and

Diplopoda

\section{General Article $\quad 300$}

Mollusks
Platygastroidea
Denmark、United Kingdom

Canada、USA

USA

生物多样性，物种列表

新种（1种）
更新的物种清单+命名法+分布

新记录（3种）

分布范围扩大 (1种)

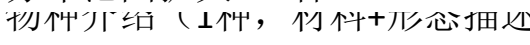

+ 诊断+分布 + 生物学) + 识别的关

USA

Brazil、Slovakia、Switzerland

USA

Russia、Czech Republic

\section{Germany}

Mexico、USA

Australia、USA、Canada
物种收集记录（47种），新记录 (30种)

新记录（21种）

物种收集记录（54种），新记录 (11种)

\section{物种注释清单（33种）}

物种名错用、修改（从不同网站 整合物种名, 查证、修改)

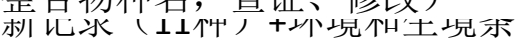

挑战使用名字链接到数字生物多 样性信息 
李俊洁, 黄晓否. 生物多样性数据论文发表趋势分析. 生物多样性, 2016, 24 (12)：1317- 1324. htt p: //www bi odi ver si ty- sci ence. net/CN/10 17520/bi ods. 2016325

$\begin{array}{lll}\text { 2016/6/6 } & \text { Taxonomic Paper } & 283 \\ \text { 2016/6/7 } & \text { Taxonomic Paper } & 176 \\ \text { 2016/6/8 } & \text { Taxonomic Paper } & 115 \\ \text { 2016/6/9 } & \text { Taxonomic Paper } & 221 \\ \text { 2016/6/13 } & \text { Taxonomic Paper } & 228\end{array}$

\begin{tabular}{|c|c|}
\hline $\begin{array}{l}\text { Hymenoptera: Chalcidoidea } \\
\text { and Mymarommatoidea }\end{array}$ & United Kingdom、 France \\
\hline $\begin{array}{l}\text { Hymenoptera:Aphelinidae; } \\
\text { Hemiptera: Aleyrodidae }\end{array}$ & United Kingdom、Taiwan \\
\hline Ehretiaceae,Boraginales & Romania、Germany \\
\hline & Canada \\
\hline Hymenoptera:Formi & USA \\
\hline
\end{tabular}

更新的物种清单+命名法+分布

新种（2种, 蚜小蜂）, 两种蚜 小蜂寄生于两种粉䖝上

分类学修订

植物集合 (维管植物、地衣、藻 类和蓝细菌），太空生物学

化 